\title{
Cardiac rehabilitation may not provide a quality of life benefit in coronary artery disease patients
}

\author{
Rosanna Tavella ${ }^{1,2}$ and John F Beltrame $e^{1,2^{*}}$
}

\begin{abstract}
Background: Improvements in patient-reported health-related quality of life (HRQOL) are important goals of cardiac rehabilitation (CR). In patients undergoing coronary angiography for angina and with documented coronary artery disease (CAD), the present study compared HRQoL over 6 months in CR participants and non-participants. Clinical predictors of $C R$ participants were also assessed.

Methods: A total of 221 consecutive patients undergoing angiography for angina with documented CAD and who were eligible for a CR program were recruited. CR participants were enrolled in a six-week Phase II outpatient CR course $(31 \%, n=68)$ within 2 months following angiography and the non-participants were included as a control. At baseline (angiography), one and six months post angiography, clinical and HRQOL data were obtained including the Short Form-36 (SF-36) and the Seattle Angina Questionnaire (SAQ). The response rate for the HRQoL assessment was $68 \%(n=150)$. Cross sectional comparisons were age-adjusted and performed using logistic or linear regression as appropriate. Longitudinal changes in $\mathrm{HRQOL}$ were assessed using least squares regression. Finally, a multiple logistic regression was fitted with CR participant as the final outcome.

Results: At angiography, the CR non-participants were older, and age-adjusted analyses revealed poorer physical (angina limitation: $54 \pm 25$ versus $64 \pm 22, \mathrm{p}<0.05$ ) and mental HRQoL (significant psycho-social distress: 62\%, $\mathrm{n}=95$ versus $47 \%, n=32, p<0.05$ ) compared to the $C R$ participants. In addition, the $C R$ participants were more likely to have undergone angiography for myocardial infarction $(\mathrm{OR}=2.8,95 \% \mathrm{Cl} 1.5-5.3, \mathrm{p}=0.001)$. By six months, all patients showed an improvement in HRQOL indices, however the rate of improvement did not differ between the controls and CR participants.

Conclusion: Following angiography, CAD patients reported improvements in both generic and disease-specific HRQoL, however CR participation did not influence this outcome. This may be explained by biases in CR enrollment, whereby acute patients, who may be less limited in HRQoL compared to stable, chronic patients, are targeted for CR participation. Further investigation is required so CR programs maximize the quality of life benefits to all potential $\mathrm{CR}$ patients.
\end{abstract}

Keywords: Coronary artery disease, Cardiac rehabilitation, Health-related quality of life

\section{Background}

Cardiac rehabilitation $(\mathrm{CR})$ programs are recognized as an effective component for the management of patients with coronary artery disease (CAD) [1,2]. Two systematic reviews of almost 50 randomised controlled trials showed a $20 \%$ reduction in all cause mortality and a $27 \%$ reduction in cardiac mortality at two to five years $[3,4]$.

\footnotetext{
* Correspondence: john.beltrame@adelaide.edu.au
'Cardiology Unit, The Queen Elizabeth Hospital, University of Adelaide, 28

* Correspondence: john.beltrame@adelaide.edu.au
${ }^{1}$ Cardiology Unit, The Queen Elizabeth Hospital, University of Adelaide, 28 Woodville Rd, Woodville South, South Australia 5011, Australia

${ }^{2}$ Discipline of Medicine, University of Adelaide, Adelaide, South Australia, ${ }^{2}$ Disciplin
Australia
}

\section{Biomed Central

(c) 2012 Tavella and Beltrame; licensee BioMed Central Ltd. This is an Open Access article distributed under the terms of the Creative Commons Attribution License (http://creativecommons.org/licenses/by/2.0), which permits unrestricted use, distribution, and reproduction in any medium, provided the original work is properly cited.
However, the impact of $\mathrm{CR}$ on health-related quality of life (HRQoL) has been inconclusive [4] due to the limited studies and the methodologies employed.

Previous CR studies have largely targeted patients with a recent MI, coronary revascularisation or cardiac failure. However all patients with CAD could potentially benefit from CR, especially those with chronic diseases who are more likely to be significantly disabled. Despite this, it appears that patients with chronic angina are less likely to participate in these programs [5], especially if they are female [6] or do not undergo revascularisation procedures. 
This study evaluated CAD patients undergoing diagnostic angiography to ascertain (i) the clinical characteristics and HRQoL of patients undergoing CR as compared to those who do not, (ii) to assess the clinical predictors of $\mathrm{CR}$ participants, and (iii) compare the 6-month HRQoL progress following angiography in those that do and do not receive CR.

\section{Methods}

This prospective, observational study recruited patients undergoing diagnostic angiography at the Queen Elizabeth Hospital (QEH) (Adelaide, Australia) between April 2003 and May 2007 and followed their progress over a 6-month period. The QEH is a tertiary hospital that provides cardiac care to the North-Western suburbs of Adelaide as well as diagnostic angiographic facilities for rural communities and smaller metropolitan hospitals. The Hospital provides Phase II CR services only for those patients residing within its local health care jurisdiction. This study was approved by the Central Northern Adelaide Health Service Ethics of Human Research Committee.

\section{Study patients}

Inclusion criteria for study enrollment included patients presenting for (i) invasive coronary angiography undertaken for the investigation of chest pain, (ii) angiographically documented obstructive CAD ( $\geq 50 \%$ stenosis in at least one epicardial coronary artery), and (iii) eligibility for Phase II CR at QEH (defined by residential location in the Western suburbs of Adelaide, Australia).

The study exclusion criteria were (a) non-coronary disorders such as aortic valve disease, and (b) inability to communicate in English/unable to complete written questionnaires.

\section{Cardiac rehabilitation program}

The QEH Phase II CR program comprises of biweekly visits held over a 6-week period. The course incorporates counseling and education on overall heart health and risk factor identification, nutrition, smoking cessation and weight loss. In addition, relaxation techniques and stress management for both patients and their partners or carers are included. A structured exercise program with an individualized exercise prescription was incorporated into each session.

\section{Study protocol}

Patients scheduled for coronary angiography for the investigation of chest pain were approached prior to the procedure and informed consent was obtained. At this time, a detailed clinical history was attained via standardized medical case-note review (conducted by clinical nurses and medical staff). At time of consent, all patients underwent a short interview with clinical nurses or trained research assistants assessing cardiovascular risk profile, and angina severity which was graded according to the Canadian Cardiovascular Society Classification (CCSC). This was followed by HRQoL assessment utilizing the selfadministered Short-Form 36 (SF-36) [7] and the Seattle Angina Questionnaires (SAQ) [8] instruments. At 1 and 6 months post-angiography, patients were re-assessed by: (a) SF-36 and SAQ mailed out for completion, (b) review of hospital administrative system for hospital admissions/ presentations and (2) follow-up phone calls made assessing angina status, medication use and clinical events.

\section{Parameters assessed}

Participation in CR was strictly defined as completion of the Phase II CR program as identified by the hospital CR services medical record system. The CR records were reviewed to identify patients who were documented as having completed the CR program at the hospital. The $\mathrm{CR}$ records at a second hospital, outside the local health care jurisdiction, were also reviewed to verify if any patients included in the study underwent CR at another nearby facility. Clinical data was obtained by medical case note review and patient interview. Socio-economic status was defined by the Australian Bureau of Statistics' Socio-Economic Indexes for Areas scores, an accepted proxy measure for socio-economic status based on regional analyses in Australia [9]. HRQoL was assessed using both a generic (SF-36) and disease specific (SAQ) questionnaire. The SF-36 is a well-established measure [7], and has been shown to have good reliability, validity and responsiveness in patients with CAD [10], and also in a CR setting [11]. Elevated psychosocial distress was identified by the SF-36 Mental Summary Score (MCS) of $\leq 45$ [12]. The SAQ is a disease-specific functional status measure quantifying five clinically relevant domains related to angina: physical limitation, angina stability, angina frequency, treatment satisfaction \& quality of life [8]. It is reported to be the most appropriate diseasespecific instrument for CAD [13].

\section{Statistical analysis}

Comparisons were made between patients who completed the Phase II CR program and those who did not participate in the program. Cross-sectional analyses between the CR participants and non-participants, for categorical or continuous variables were performed using either logistic or linear regression respectively, and age adjusted where appropriate. Longitudinal changes in SF-36 and SAQ scores from baseline to 6 months between the CR groups were compared utilising either random effects generalised least square or fixed effects ordinary least squares regression [14]. A multiple logistic regression was fitted with CR attendance as the final outcome. Variables identified for the multivariate analysis were selected following univariate 
tests significant at a $p$ value level of 0.25 . The final model was obtained using automatic backward elimination, and the final odds ratios (ORs) with 95\% CIs and $p$ values are reported. All analyses were performed with STATA (Version 11, StataCorp, Texas, USA).

\section{Missing HRQoL data management}

Follow-up HRQoL data over the 6 months was available in $68 \%$ of patients undergoing coronary angiography. To account for possible missing value bias, multiple imputation techniques [15] were used, conditioned upon the available SAQ and SF-36 scores. Imputation was performed by chained equations utilising switching regression, an iterative multivariable regression technique [16]. The data analysis was then repeated using the above-described methods but no significant deviation from the original models were observed. The HRQoL results presented below are those from the imputed data analysis.

\section{Results}

Between 28th April 2003 and 11th April 2007, 828 patients with angiographic evidence of CAD were identified and consented. Of these, 221 (27\%) were eligible for referral to TQEH Phase II cardiac rehabilitation services and were recruited into the study. Figure 1 shows the Study Flow Diagram. Of these patients, 68 (31\%) participated and completed the Phase II CR with almost $70 \%(\mathrm{n}=46)$ commencing the program within one month of coronary angiography. The mean waiting time for enrolment was 1.7 months ( $\mathrm{SD}=2.15,95 \%$ CI 1.16-2.22).

\section{Baseline characteristics of study patients Demographic and clinical features}

Patients attending Phase II CR were significantly younger compared to patients who did not attend CR and thus subsequent analyses were age-adjusted. In relation to socioeconomic status, $24 \%(n=37)$ of CR patients were identified as belonging to low, which was comparable to $16 \%(\mathrm{n}=11)$ in the CR non-participants (Table 1). The CR patients were more likely to have undergone angiography following an admission with an acute coronary syndrome (ACS) (Table 2), with 41\% $(\mathrm{n}=62)$ having experienced a recent myocardial infarction compared with $17 \%(\mathrm{n}=12)$ who did not have $\mathrm{CR}(\mathrm{p}<0.001)$. Despite this, the extent of angiographic disease was similar between groups as was the initial therapy although there was a slight trend towards medical therapy for those not participating in CR (Table 2).

\section{HRQoL indices}

Scores on the HRQoL indices indicated the CR patients had a better quality of life in terms of both general health status and angina-specific morbidity at baseline (Table 2). Scores on the physical limitation domain of the SAQ were significantly higher in the CR patients compared to $\mathrm{CR}$ non-participants. The angina frequency domain was also higher (indicating less angina) in the CR patients, however this was not statistically significant. Consistent with this, scores on the SF-36 PCS tended to be higher in the $\mathrm{CR}$ patients. In addition, elevated psychosocial distress as identified by the SF-36 MCS, was lower in the CR patients (Table 2).

\section{Predictors of CR participation}

Predictors of $C R$ participation were assessed in the overall group of patients presenting for angiography who were potentially eligible for referral. Following univariate analysis, backward elimination retained the following predictors: age, recent myocardial infarction and a prior history of musculoskeletal disease. In the final model, only recent myocardial infarction $(\mathrm{OR}=2.8,95 \%$ CI 1.5-5.3, $\mathrm{p}=0.001$ ) remained as a significant predictor of $\mathrm{CR}$ participation.

\section{Six month outcomes in study patients Clinical outcomes}

At 6 months following angiography, at which time the $\mathrm{CR}$ patients had completed their rehabilitation programme, there were no differences between groups in relation to cardiac events (Table 3). Furthermore there were no differences between groups in changes in medical therapy or angina limitations as assessed via the CSCC system (Table 3).

\section{HRQoL indices}

Figures 2 and 3 summarise the HRQoL indices over the 6 -month period for the 2 study groups. The HRQoL indices were measured at 1 and 6 months although at the 1 -month assessment time point, only $70 \%(n=46)$ of the CR participants had commenced the program and none had completed the 6-week program. By 6 months, all the $\mathrm{CR}$ participants had completed the CR program. The SAQ-derived physical limitation, angina frequency, and quality of life scales all showed significant improvement over the 6-month study period. Both study groups also demonstrated statistically significant improvements in the SF-36 PCS and MCS over the 6-month period. However, no differences were observed in the rate of improvement from baseline over 6 months between the two groups in SAQ and SF-36 scores (Figures 2 and 3). Furthermore, cross-sectional analysis on the 1 and 6 month endpoints revealed no significant differences for both the SAQ and SF-36 scales between the two groups.

\section{Discussion}

This case-control study assessed the clinical characteristics of patients with angiographically-documented CAD who underwent $\mathrm{CR}$ and assessed their subsequent clinical and 


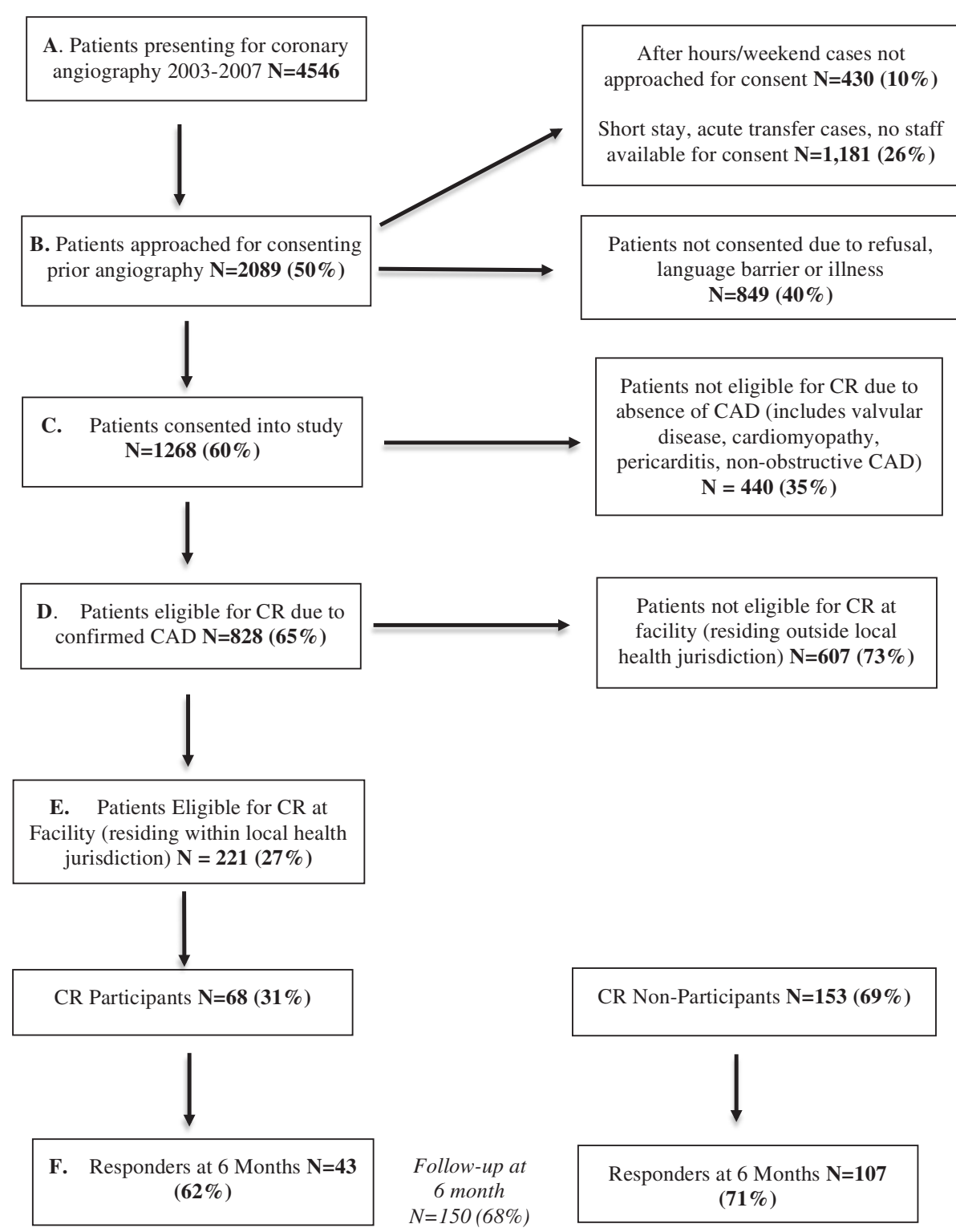

Figure 1 Flow Chart Describing Patients Presenting for Coronary Angiography and Eligible for Cardiac Rehabilitation at the Queen Elizabeth Hospital. Study flow diagram describing (a) the number of patients undergoing coronary angiography during the recruitment period, (b) the number of patients who were approached for consent, (c) reasons for no consent and exclusion, (d) the number of patients with confirmed CAD, (e) the number of patients who were eligible for CR program and (f) the response rate of CR participants and non-participants.

HRQoL progress over a 6-month period. The key findings from this study are (i) patients who undertake CR are younger and most likely to have experienced a recent myocardial infarction; and (ii) in the 6-month follow-up period, all patients showed an improvement in HRQoL indices independent of whether or not they had CR with no significant incremental benefit found in those who did have $\mathrm{CR}$.

\section{Patient selection for cardiac rehabilitation}

Typically, CR has been targeted towards CAD patients who have experienced a recent MI [17] or undergone revascularisation therapies [18]. In this study, two-thirds of the CR patients had experienced a recent ACS, and this was the defining clinical characteristic of the cohort. Although it is paramount that all patients with an ACS be offered $\mathrm{CR}$, it is equally important that stable patients with documented CAD should be offered CR. Indeed, as shown in our study, those who did not undertake CR were more chronically disabled, older, more physically disabled, more frequently identified with psychosocial distress and more often had a history of chronic stable angina (Table 1). Hence those who did not undertake CR may potentially have benefited more than those who 
Table 1 Baseline clinical characteristics between CR participants and non-Participants

\begin{tabular}{|c|c|c|c|c|c|c|}
\hline & $n$ & 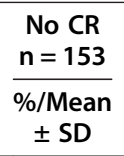 & $n$ & $\begin{array}{c}\text { CR } \\
\mathrm{n}=68 \\
\begin{array}{c}\% / \text { Mean } \\
\pm \text { SD }\end{array}\end{array}$ & & $\begin{array}{c}\begin{array}{c}\text { Total } \\
\mathrm{N}=221\end{array} \\
\begin{array}{c}\text { \%/Mean } \\
\pm \mathrm{SD}\end{array}\end{array}$ \\
\hline \multicolumn{7}{|c|}{ Cardiovascular Risk Factors } \\
\hline Age (years) & 153 & $65 \pm 12^{*}$ & 68 & $60 \pm 12^{* *}$ & 221 & $63 \pm 12$ \\
\hline Female & 153 & $31 \%$ & 68 & $24 \%$ & 221 & $29 \%$ \\
\hline Current Smoker & 148 & $18 \%$ & 68 & $21 \%$ & 216 & $19 \%$ \\
\hline Ex-smoker & 147 & $45 \%$ & 68 & $34 \%$ & 215 & $41 \%$ \\
\hline Hypertension & 152 & $63 \%$ & 67 & $55 \%$ & 219 & $61 \%$ \\
\hline Diabetes Mellitus & 149 & $33 \%$ & 67 & $28 \%$ & 216 & $31 \%$ \\
\hline Hypercholesterolaemia & 149 & $74 \%$ & 68 & $71 \%$ & 217 & $73 \%$ \\
\hline \multicolumn{7}{|l|}{ Co-morbidities } \\
\hline $\begin{array}{l}\text { Previous Myocardial } \\
\text { Infarct }\end{array}$ & 152 & $32 \%$ & 68 & $32 \%$ & 220 & $32 \%$ \\
\hline Prior Revascularisation & 153 & $28 \%$ & 68 & $24 \%$ & 221 & $27 \%$ \\
\hline Cerebrovascular disease & 149 & $10 \%$ & 63 & $2 \%$ & 212 & $8 \%$ \\
\hline $\begin{array}{l}\text { Chronic obstructive } \\
\text { pulmonary disease }\end{array}$ & 149 & $28 \%$ & 63 & $13 \% *$ & 212 & $24 \%$ \\
\hline $\begin{array}{l}\text { Peripheral arterial } \\
\text { disease }\end{array}$ & 149 & $7 \%$ & 63 & $3 \%$ & 212 & $6 \%$ \\
\hline $\begin{array}{l}\text { Gastroesophageal } \\
\text { disorders }\end{array}$ & 149 & $41 \%$ & 65 & $32 \%$ & 214 & $38 \%$ \\
\hline Musculoskeletal disease & 149 & $14 \%$ & 63 & $22 \%$ & 212 & $17 \%$ \\
\hline Psychiatric disorders & 147 & $25 \%$ & 64 & $17 \%$ & 211 & $23 \%$ \\
\hline \multicolumn{7}{|c|}{ Indication for Angiography } \\
\hline $\begin{array}{l}\text { Recent Acute Coronary } \\
\text { Syndrome }\end{array}$ & 150 & $41 \%$ & 66 & $65 \% * *$ & 216 & $49 \%$ \\
\hline Chronic Stable Angina & 150 & $55 \%$ & 66 & $33 \% * *$ & 216 & $51 \%$ \\
\hline $\begin{array}{l}\text { Low Socioeconomic } \\
\text { status }\end{array}$ & 153 & $24 \%$ & 68 & $16 \%$ & 221 & $22 \%$ \\
\hline $\begin{array}{l}\text { CCS II-IV at } \\
\text { Angiography }\end{array}$ & 141 & $61 \%$ & 63 & $51 \%$ & 204 & $58 \%$ \\
\hline
\end{tabular}

did. Unfortunately this study does not provide insights into why patients did/did not participate in the Phase II CR program, thus it may reflect a selection bias by the health care system or patient choice.

Regardless of the reason, the findings of this study suggest that patients with chronic stable angina need to be targeted for enrolment to a CR program and this may be best undertaken at the time of diagnostic angiography. Targeting $\mathrm{CR}$ to patients undergoing revascularisation therapies is important and will provide $C R$ to some chronic stable angina patients. However this study showed that those who did not receive CR tended to be managed with medical therapy (Table 2). Moreover, CR in stable angina patients has been shown to be superior to percutaneous coronary intervention in increasing
Table 2 Baseline cardiac history \& HRQoL characteristics between CR participants and non-Participants

\begin{tabular}{|c|c|c|c|c|}
\hline & $\mathbf{n}$ & No $C R(n=153)$ & $\mathbf{n}$ & $C R(n=68)$ \\
\hline \multicolumn{5}{|c|}{ Pre-Angiography Cardioprotective Therapy } \\
\hline Anti-platelet & 153 & $84 \%$ & 68 & $82 \%$ \\
\hline Beta-blockers & 153 & $35 \%$ & 68 & $19 \%$ \\
\hline Statins & 153 & $67 \%$ & 68 & $66 \%$ \\
\hline ACE-inhibitor & 153 & $42 \%$ & 68 & $40 \%$ \\
\hline Angiotensin Receptor Blocker & 153 & $18 \%$ & 68 & $13 \%$ \\
\hline \multicolumn{5}{|l|}{ Obstructive CAD Findings } \\
\hline Single Vessel Disease & 153 & $29 \%$ & 68 & $32 \%$ \\
\hline Double Vessel Disease & & $39 \%$ & & $32 \%$ \\
\hline Triple Vessel Disease & & $32 \%$ & & $35 \%$ \\
\hline \multicolumn{5}{|l|}{ Initial Treatment Strategy } \\
\hline Medical Therapy & 153 & $56 \%$ & 68 & $41 \%$ \\
\hline Coronary Angioplasty/stent & & $30 \%$ & & $43 \%$ \\
\hline Coronary bypass graft & & $14 \%$ & & $16 \%$ \\
\hline \multicolumn{5}{|l|}{ Seattle Angina Questionnaire } \\
\hline Physical Limitation & 153 & $54 \pm 25$ & 68 & $64 \pm 22^{*}$ \\
\hline Angina Stability & 153 & $37 \pm 31$ & 68 & $40 \pm 34$ \\
\hline Angina Frequency & 153 & $59 \pm 27$ & 68 & $66 \pm 27$ \\
\hline Treatment Satisfaction & 153 & $90 \pm 16$ & 68 & $89 \pm 18$ \\
\hline Quality of Life & 153 & $42 \pm 22$ & 68 & $44 \pm 24$ \\
\hline \multicolumn{5}{|l|}{ Short-Form 36} \\
\hline Physical Summary Score & 153 & $34 \pm 11$ & 68 & $38 \pm 11$ \\
\hline Mental Summary Score & 153 & $42 \pm 11$ & 68 & $43 \pm 11$ \\
\hline Elevated Psychosocial Distress & 153 & $62 \%$ & 68 & $47 \% *$ \\
\hline
\end{tabular}

${ }^{*} \mathrm{p}<0.05,{ }^{* *} \mathrm{p}<0.01$, age adjusted.

exercise capacity and reducing hospital readmissions [19]. Thus an active program to target CR for disabled chronic stable angina patients needs to be considered.

\section{The impact of cardiac rehabilitation on HRQoL}

Improvement in HRQoL following $\mathrm{CR}$ has not been consistently documented as highlighted in a meta-analysis, which demonstrated that improvement in HRQoL with CR was better than in controls in only two of 12 trials [4]. However, comparing HRQoL findings in CR research is difficult due to the diversity of the instruments used. Earlier studies often used psychosocial well-being measures $[5,6,20]$ rather than established generic and disease-specific instruments. Although more recent trials have increasingly employed the SF-36, there are still conflicting accounts concerning the influence of $\mathrm{CR}$ on HRQoL [21-24]. In addition, only few studies have used a disease-specific measure, however the choice of instrument has varied, and have included the MacNew $[25,26]$, the Cardiac Quality of Life Index [27], 
Table 3 Clinical progress over 6 months following angiography

\begin{tabular}{|c|c|c|c|c|c|c|c|}
\hline & $n$ & $\frac{\text { No CR }}{\%}$ & $n$ & $\frac{\mathrm{CR}}{\%}$ & $n$ & $\frac{\text { Total }}{\%}$ & $\begin{array}{c}p \\
\text { Age } \\
\text { adjusted }\end{array}$ \\
\hline $\begin{array}{l}\text { CCS Class II-IV } 6 \\
\text { Months }\end{array}$ & 78 & $17 \%$ & 34 & $21 \%$ & 112 & $18 \%$ & 0.593 \\
\hline \multicolumn{8}{|l|}{ Medication Changes } \\
\hline Any Changes & 126 & $68 \%$ & 60 & $68 \%$ & 186 & $68 \%$ & 0.965 \\
\hline Started Nitrates & 125 & $22 \%$ & 60 & $25 \%$ & 185 & $23 \%$ & 0.562 \\
\hline Started CCB & 126 & $22 \%$ & 60 & $13 \%$ & 186 & $19 \%$ & 0.165 \\
\hline Started Beta Blocker & 126 & $14 \%$ & 60 & $13 \%$ & 186 & $14 \%$ & 0.929 \\
\hline $\begin{array}{l}\text { Started Any } \\
\text { Anti-anginal }\end{array}$ & 126 & $44 \%$ & 60 & $45 \%$ & 186 & $44 \%$ & 0.757 \\
\hline \multicolumn{8}{|l|}{ Cardiac Endpoints } \\
\hline $\begin{array}{l}\text { ED Chest Pain } \\
\text { Presentation }\end{array}$ & 128 & $16 \%$ & 59 & $10 \%$ & 187 & $14 \%$ & 0.263 \\
\hline $\begin{array}{l}\text { Chest pain } \\
\text { re-admission }\end{array}$ & 127 & $16 \%$ & 59 & $10 \%$ & 186 & $14 \%$ & 0.345 \\
\hline Myocardial infarction & 127 & $2 \%$ & 59 & $0 \%$ & 186 & $2 \%$ & \\
\hline Repeat angiography & 127 & $4 \%$ & 59 & $3 \%$ & 186 & $4 \%$ & 0.646 \\
\hline $\mathrm{PCl}$ & 126 & $13 \%$ & 60 & $20 \%$ & 186 & $15 \%$ & 0.401 \\
\hline CABG & 126 & $24 \%$ & 59 & $22 \%$ & 185 & $23 \%$ & 0.905 \\
\hline Mortality & 153 & $2 \%$ & 68 & $1 \%$ & 221 & $2 \%$ & 0.844 \\
\hline MI/Mortality & 153 & $3 \%$ & 68 & $1 \%$ & 221 & $3 \%$ & 0.659 \\
\hline
\end{tabular}

and Quality of Life after Myocardial Infarction [28]. Hofer et al [29] highlights that a consistent application of a single disease-specific measure is warranted in $\mathrm{CR}$ research. Although the SAQ is an established and arguably the best disease-specific measure for CAD [13], the present study is the first to utilize the SAQ in a CR setting.

\section{Study implications for cardiac rehabilitation}

The failure of CR to impact on HRQoL in this and other studies warrants further consideration as it may reflect nuances relating to these studies rather than CR being ineffective. These include factors relating to the patient, the CR therapy and the study design.

\section{Patient factors}

As discussed above and reported in previous studies [30], the patients who did not participate in CR were the most disabled and thus may well have been those that would have derived the most benefit. Five patient-related factors may have influenced the findings in this study and should be closely considered in further studies. Firstly, CR efficacy in relation to impact on HRQoL has been shown to be age-dependent with previous studies reporting that younger (i.e. $<41$ years) and older ( $>65$ years) patients benefitting the most from $\mathrm{CR}$ with no benefits observed in those 41-65 years [21,29]. In this study, the average age of the CR participants was 60 years, which may have influenced the findings. Secondly, almost half of the CR patients were identified as experiencing elevated
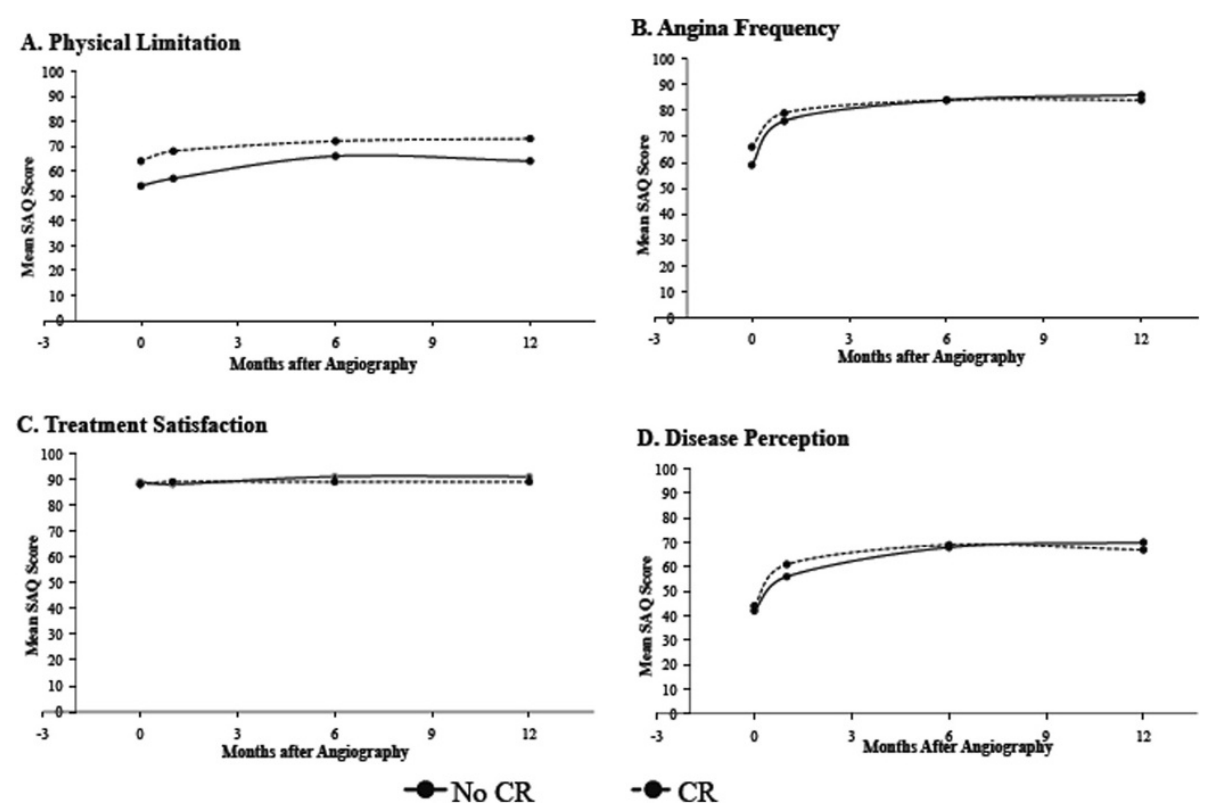

Figure 2 A-D. SAQ Domain Scores Over Six Months in CR Participants and Non-Participants. SAQ domain scores from baseline to six months compared between cardiac rehabilitation participants and non-participants. Longitudinal analysis revealed no significant differences in the rate or extent of improvement in the scores between CR participants and non-participants. 


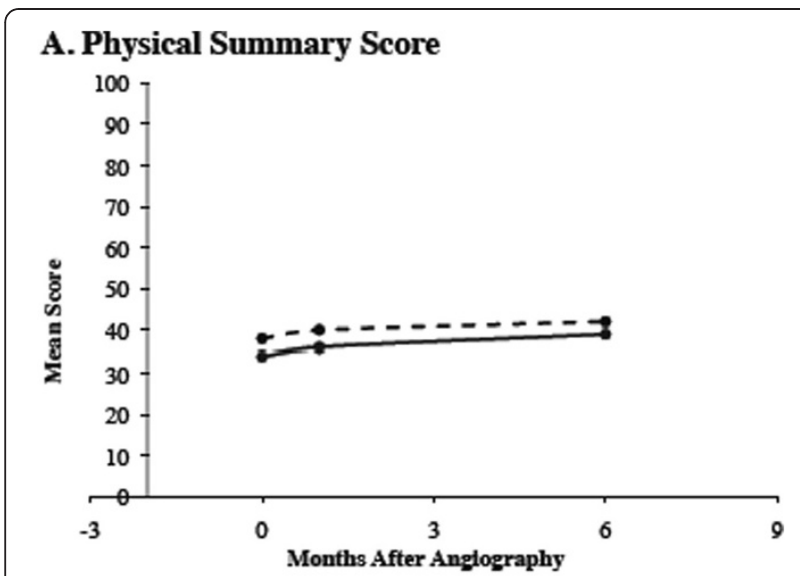

B. Mental Summary Score

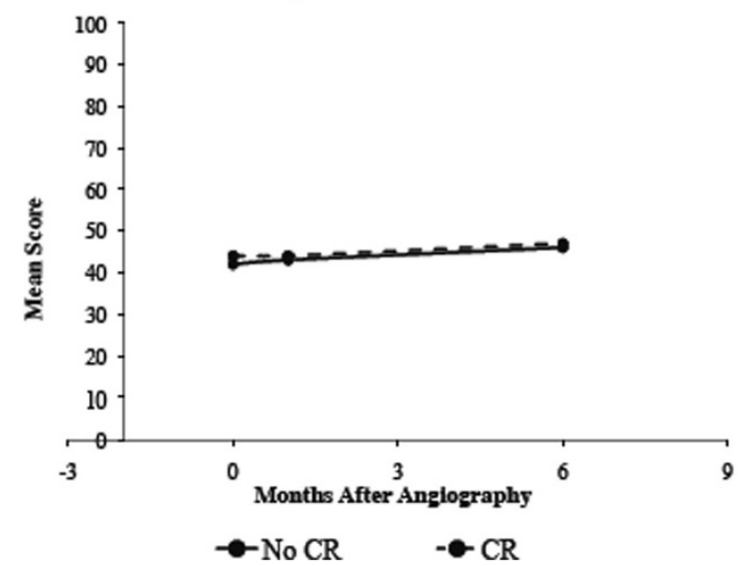

Figure $3 \mathrm{~A}$ and B.SF-36 Summary Scores Over Six Months. SF-36 Physical (A) and Mental Summary Score (B) from baseline to six months compared between cardiac rehabilitation participants and non-participants. Longitudinal analysis revealed no significant differences in the rate or extent of improvement in the scores between CR participants and non-participants.

psychosocial distress and this has a major impact on HRQoL. Thus if the CR program also focused on the treatment of psychosocial distress, an incremental improvement in HRQoL may have also been achieved. Thirdly, the CR study population predominantly underwent this therapy following a recent myocardial infarct. Muller-Nordhorn et al [21] showed that only patients undergoing $\mathrm{CR}$ following revascularisation procedures showed improvement in their SF-36 scores whereas recent myocardial infarct patients did not. Fourthly, patient participation in CR was $31 \%$, which is comparable to rates reported by other studies, which have shown $14-43 \%$ of potential cardiac patients participate in CR programs [3133]. Although all the study patients were eligible for CR, why the non-participants did not avail themselves to this opportunity is unclear. The focus by the health workers on the acute presentation $[34,35]$ may have underemphasized the importance in chronic conditions and thus education of both health care workers and patients is required. Logistic factors may have also influenced patient participation, such as transport availability/cost and session times. Finally, although all the CR patients completed the program, the commitment they made to the therapy was not assessed.

\section{The CR therapy}

$\mathrm{CR}$ programs are heterogeneous in content although professional societies are developing guidelines with core components to standardize the therapy [36,37]. Hence the findings from this study may not be applicable to other CR programs. In particular, tailored programs for different CAD presentations or populations may be useful to maximize benefits for patients, as suggested by Piepoli et al [38]. For example, tailored gender-specific programs have been shown to provide increased quality of life improvement for women [39]. Other aspects that require further considerations include $C R$ program delivery and duration. The hospital-based CR program in this study may be better delivered as a telephone or on-line program, which may assist in patient participation and provide long-term access to all. This is important since recent studies have shown that a continued intervention following $\mathrm{CR}$ is effective in improving cardiovascular outcomes [40,41]. Also the duration of the CR program in this study was only 6 weeks whereas Piepoli [38] highlights that such short-term approaches are unlikely to yield long-term benefits or impact on quality of life.

\section{Study design}

The current study was a longitudinal case-control design and the limitations of this design may have influenced the findings. Firstly, the non-randomised allocation to CR therapy may have been influenced by a selection bias although the two groups were similar in their baseline HRQoL indices. Secondly, the study period was limited to 6 months and longer follow-up periods may have influenced the results. Of note, a meta-analysis of $\mathrm{CR}$ therapies showed improvement in all-cause mortality only at 3-year follow-up and not earlier [42]. Thirdly, important information such as referral and drop out rates, reasons for non-inclusion in $\mathrm{CR}$, such as ambulation, were not available in this study. The lack of standardized data collection and thus insufficient program information causes difficulty when assessing biases [43]. Lastly, although the study was powered to detect a difference of 6 points on the SF-36 PCS, the total sample size was relatively small; larger studies are required and should investigate smaller but clinically relevant differences in HRQoL. It should also be noted that HRQoL assessment is best undertaken by patient interview where possible as opposed to mail-out surveys to increase response rate. 


\section{Conclusion}

The importance of $\mathrm{CR}$ in reducing cardiac events amongst patients with established CAD has been previously established, however its benefit in improving HRQoL is less clear and has not been affirmed in this study. This study has shown that those CAD patients who do not undergo CR are usually more disabled with chronic disorders and thus may potentially be those who would derive the most benefit from this therapy. Thus further studies are required to identify which patients will receive the optimal benefit from $C R$ therapy rather than simply targeting those who have experienced a recent ACS.

\section{Competing interests}

The authors declare that they have not competing interests.

\section{Authors' contributions}

JB conceived the study, and participated in its design and helped draft the manuscript. RT participated in the study design, carried out the patient assessments, performed the statistical analysis and drafted the manuscript. Each author has read and approved the final manuscript.

\section{Acknowledgement}

The authors wish to acknowledge Renee Henthorn, Sue Sierp, the Lyell McEwin and Queen Elizabeth Hospitals Cardiac Rehabilitation teams for their valuable assistance in undertaking this study.

\section{Funding and support}

Professor John Beltrame is supported by a South Australian Cardiovascular Research Development Program Fellowship.

Rosanna Tavella is supported by The Queen Elizabeth Hospital Research Foundation Postgraduate Scholarship.

Received: 10 April 2012 Accepted: 7 November 2012

Published: 19 November 2012

\section{References}

1. Ades PA: Cardiac rehabilitation and secondary prevention of coronary heart disease. N Engl J Med 2001, 345:892-902.

2. Dalal HM, Zawada A, Jolly K, Moxham T, Taylor RS: Home based versus centre based cardiac rehabilitation: Cochrane systematic review and meta-analysis. BMJ 2010, 340:b5631.

3. Jolliffe JA, Rees K, Taylor RS, Thompson D, Oldridge N, Ebrahim S: Exercisebased rehabilitation for coronary heart disease. Cochrane Database Syst Rev 2001, 1-62. CD001800.

4. Taylor RS, Brown A, Ebrahim S, et al: Exercise-based rehabilitation for patients with coronary heart disease: systematic review and metaanalysis of randomized controlled trials. Am J Med 2004, 116:682-692.

5. Daly J, Sindone AP, Thompson DR, Hancock K, Chang E, Davidson P: Barriers to participation in and adherence to cardiac rehabilitation programs: a critical literature review. Prog Cardiovasc Nurs 2002, 17:8-17.

6. Ades PA, Waldmann ML, Polk DM, Coflesky JT: Referral patterns and exercise response in the rehabilitation of female coronary patients aged greater than or equal to 62 years. Am J Cardiol 1992, 69:1422-1425.

7. Ware JE, Snow KK, Kosinski M, Gandek B: SF-36 health survey: manual and interpretation guide. Boston: The Health Institute, New England Medical Center; 1993.

8. Spertus JA, Winder JA, Dewhurst TA, et al: Development and evaluation of the Seattle Angina Questionnaire: a new functional status measure for coronary artery disease. J Am Coll Cardiol 1995, 25:333-341.

9. ABS: Socio-economic indexes for areas, Australia, 2001. Canberra: Australian Bureau of Statistics; 2003.

10. McHorney CA, Ware JE Jr, Lu JF, Sherbourne CD: The MOS 36-item Short-Form Health Survey (SF-36): III. Tests of data quality, scaling assumptions, and reliability across diverse patient groups. Med Care 1994, 32:40-66.
11. Jette DU, Downing J: Health status of individuals entering a cardiac rehabilitation program as measured by the medical outcomes study 36-item short-form survey (SF-36). Phys Ther 1994, 74:521-527.

12. Tavella R, Air T, Tucker G, Adams R, Beltrame JF, Schrader G: Using the Short Form-36 mental summary score as an indicator of depressive symptoms in patients with coronary heart disease. Qual Life Res 2010, 19:1105-1113

13. Dougherty CM, Dewhurst T, Nichol WP, Spertus J: Comparison of three quality of life instruments in stable angina pectoris: Seattle Angina Questionnaire, Short Form Health Survey (SF-36), and Quality of Life Index-Cardiac Version III. J Clin Epidemiol 1998, 51:569-575.

14. Stock J, Waston M: Regression with panel data. In Introduction to econometrics. Edited by Stock J, Watson M. Boston: Addison Wesley Higher Education; 2003.

15. Rubin D: Multiple imputation for Non-response in surveys. New York: Wiley; 1987.

16. van Buuren S, Boshuizen HC, Knook DL: Multiple imputation of missing blood pressure covariates in survival analysis. Stat Med 1999, 18:681-694.

17. Ades PA, Huang D, Weaver SO: Cardiac rehabilitation participation predicts lower rehospitalization costs. Am Heart J 1992, 123:916-921.

18. Hedback B, Perk J, Hornblad M, Ohlsson U: Cardiac rehabilitation after coronary artery bypass surgery: 10-year results on mortality, morbidity and readmissions to hospital. J Cardiovasc Risk 2001, 8:153-158.

19. Hambrecht R, Walther C, Mobius-Winkler S, et al: Percutaneous coronary angioplasty compared with exercise training in patients with stable coronary artery disease: a randomized trial. Circulation 2004, 109:1371-1378.

20. Bunker S, McBurney $\mathrm{H}$, Cox $\mathrm{H}$, Jelinek M: Identifying participation rates at outpatient cardiac rehabilitation programs in Victoria, Australia. J Cardiopulm Rehabil 1999, 19:334-338.

21. Muller-Nordhorn J, Kulig M, Binting S, et al: Change in quality of life in the year following cardiac rehabilitation. Qual Life Res 2004, 13:399-410.

22. Hawkes AL, Nowak M, Speare R: Short Form-36 Health Survey as an evaluation tool for cardiac rehabilitation programs: is it appropriate? J Cardiopulm Rehabil 2003, 23:22-25.

23. Pasquali SK, Alexander KP, Coombs LP, Lytle BL, Peterson ED: Effect of cardiac rehabilitation on functional outcomes after coronary revascularization. Am Heart J 2003, 145:445-451.

24. Izawa K, Hirano Y, Yamada S, Oka K, Omiya K, lijima S: Improvement in physiological outcomes and health-related quality of life following cardiac rehabilitation in patients with acute myocardial infarction. Circ J 2004, 68:315-320.

25. Benzer W, Platter M, Oldridge NB, et al: Short-term patient-reported outcomes after different exercise-based cardiac rehabilitation programmes. Eur J Cardiovasc Prev Rehabil 2007, 14:441-447.

26. Yohannes AM, Doherty P, Bundy C, Yalfani A: The long-term benefits of cardiac rehabilitation on depression, anxiety, physical activity and quality of life. J Clin Nurs 2010, 19:2806-2813.

27. Kennedy MD, Haykowsky M, Daub B, Van Lohuizen K, Knapik G, Black B: Effects of a comprehensive cardiac rehabilitation program on quality of life and exercise tolerance in women: a retrospective analysis. Curr Control Trials Cardiovasc Med 2003, 4:1.

28. Oldridge N, Guyatt G, Jones N, et al: Effects on quality of life with comprehensive rehabilitation after acute myocardial infarction. Am J Cardiol 1991, 67:1084-1089.

29. Hofer S, Kullich W, Graninger U, et al: Cardiac rehabilitation in Austria: long term health-related quality of life outcomes. Health Qual Life Outcomes 2009, 7:99.

30. Harlan WR 3rd, Sandler SA, Lee KL, Lam LC, Mark DB: Importance of baseline functional and socioeconomic factors for participation in cardiac rehabilitation. Am J Cardiol 1995, 76:36-39.

31. Bethell HJ, Turner SC, Evans JA, Rose L: Cardiac rehabilitation in the United Kingdom. How complete is the provision? J Cardiopulm Rehabil 2001, 21:111-115

32. Kotseva K, Wood D, De Backer G, De Bacquer D, Pyorala K, Keil U: EUROASPIRE III: a survey on the lifestyle, risk factors and use of cardioprotective drug therapies in coronary patients from 22 European countries. Eur J Cardiovasc Prev Rehabil 2009, 16:121-137.

33. Blackburn GG, Foody JM, Sprecher DL, Park E, Apperson-Hansen C, Pashkow FJ: Cardiac rehabilitation participation patterns in a large, tertiary care center: evidence for selection bias. J Cardiopulm Rehabil 2000, 20:189-195 
34. Corra U, Piepoli MF, Carre F, et al: Secondary prevention through cardiac rehabilitation: physical activity counselling and exercise training: key components of the position paper from the Cardiac Rehabilitation Section of the European Association of Cardiovascular Prevention and Rehabilitation. Eur Heart J 2010, 31:1967-1974.

35. Cortes O, Arthur HM: Determinants of referral to cardiac rehabilitation programs in patients with coronary artery disease: a systematic review. Am Heart J 2006, 151:249-256.

36. Balady GJ, Ades PA, Comoss P, et al: Core components of cardiac rehabilitation/secondary prevention programs: A statement for healthcare professionals from the American Heart Association and the American Association of Cardiovascular and Pulmonary Rehabilitation Writing Group. Circulation 2000, 102:1069-1073.

37. British Association for Cardiovascular Prevention and Rehabilitation: The BACPR Standards and Core Components for Cardiovascular Disease Prevention and Rehabilitation 2012. 2nd edition. United Kingdom; 2012.

38. Piepoli MF, Corra U, Benzer W, et al: Secondary prevention through cardiac rehabilitation: from knowledge to implementation. A position paper from the cardiac rehabilitation section of the European association of cardiovascular prevention and rehabilitation. Eur J Cardiovasc Prev Rehabil 2010, 17:1-17.

39. Beckie TM, Beckstead JW, Schocken DD, Evans ME, Fletcher GF: The effects of a tailored cardiac rehabilitation program on depressive symptoms in women: A randomized clinical trial. Int J Nurs Stud 2010, 48:3-12.

40. Giannuzzi P, Temporelli PL, Marchioli R, et al: Global secondary prevention strategies to limit event recurrence after myocardial infarction: results of the GOSPEL study, a multicenter, randomized controlled trial from the Italian Cardiac Rehabilitation Network. Arch Intern Med 2008, 168:2194-2204.

41. Wood DA, Kotseva K, Connolly S, et al: Nurse-coordinated multidisciplinary, family-based cardiovascular disease prevention programme (EUROACTION) for patients with coronary heart disease and asymptomatic individuals at high risk of cardiovascular disease: a paired, cluster-randomised controlled trial. Lancet 2008, 371:1999-2012.

42. Chew DP, Aroney CN, Aylward PE, et al: 2011 Addendum to the national heart foundation of Australia/cardiac society of Australia and New Zealand guidelines for the management of acute coronary syndromes (ACS) 2006. Heart Lung Circ 2011, 20:487-502.

43. Davies P, Taylor F, Beswick A, et al: Promoting patient uptake and adherence in cardiac rehabilitation. Cochrane Database Syst Rev 2010 7:1-39. CD007131.

doi:10.1186/1472-6963-12-406

Cite this article as: Tavella and Beltrame: Cardiac rehabilitation may not provide a quality of life benefit in coronary artery disease patients. $B M C$ Health Services Research 2012 12:406.

\section{Submit your next manuscript to BioMed Central and take full advantage of:}

- Convenient online submission

- Thorough peer review

- No space constraints or color figure charges

- Immediate publication on acceptance

- Inclusion in PubMed, CAS, Scopus and Google Scholar

- Research which is freely available for redistribution

Submit your manuscript at www.biomedcentral.com/submit
Ciomed Central 